\begin{tabular}{cc}
\hline International Journal of Engineering \& Technology \\
SPC \\
Website: $w$ ww.sciencepubco.com/index.php/IJET \\
Research paper
\end{tabular}

\title{
Mean-Variance Portfolio Optimization on Islamic Stocks by Using Non Constant Mean and Volatility Models and Genetic Algorithm
}

\author{
Endang Soeryana Hasbullah ${ }^{1 *}$, Nurfadhlina bt Abdul Halim² ${ }^{2}$, Sukono $^{3}$, Adam Sukma Putra ${ }^{4}$ and Abdul Talib Bon ${ }^{5}$ \\ 1,3 Department of Mathematics, FMIPA Universitas Padjadjaran \\ ${ }^{2}$ School of Informatics and Applied Mathematics, Universiti Malaysia Terengganu \\ ${ }^{4}$ Department of Geophysics, FMIPA Universitas Padjadjaran \\ ${ }^{5}$ Department of Technology and management, Universiti Tun Hussein Onn, Malaysia \\ *Corresponding Author Email: endangsoeryana@yahoo.co.id
}

\begin{abstract}
The risk in stock market has taken an sinificant issue in investment of stock market, including Investment in some Islamic stocks. In order to minimize the level of risk, investors usually forming an investment portfolio. Establishment of a portfolio consisting of several Islamic stocks are intended to get the optimal composition of the investment portfolio. This paper discussed about optimizing investment portfolio of Mean-Variance to Islamic stocks by using mean and volatility is not constant approaches. Non constant mean analyzed using models Autoregressive Moving Average (ARMA), while non constant volatility models are analyzed using the Generalized Autoregressive Conditional heteroscedastic (GARCH). Optimization process is performed by using the Lagrangian multiplier technique followed by the Genetic Algorithm (GA). The expected result is to get the proportion of investment in each Islamic stock analyzed. Based on the result, we got that GA give a proportion of portfolio optimum selection with the best expected return. However, The GA has more potential candidate of solution that give the investor an alternative of their optimum portfolio selection. in this paper, we only present the best solution which has the highest fitness to the model.
\end{abstract}

Keywords: Investment risk, portfolio Mean-Variance, ARMA models, GARCH models, Lagrangian multiplier, genetic Algorithm

\section{Introduction}

Investment is basically invest some capital into some form of instrument (asset), can be either fixed assets or financial assets. Investing in financial assets can generally be done by buying shares in the stock market. Investing in stocks, investors will be exposed to the risk that the magnitude of the problem along with the magnitude of the expected return [7]. The greater the expected return, generally the greater the risk to be faced. Investment risk is describing rise and fall stock price changes at any time can be measured by the value of variance [13].

The strategy is often used by investors in the face of the risks of investing is to form an investment portfolio. Establishment of an investment portfolio is essentially allocates capital in a few selected stocks, or often referred to diversify investments [9]. The purpose of the establishment of the investment portfolio is to get a certain return with minimum risk levels, or to get maximum returns with limited risk. To achieve these objectives, the investor is deemed necessary to conduct analysis of optimal portfolio selection. Analysis of portfolio selection can be done with optimum investment portfolio optimization techniques [12].

Therefore, this paper studied the paper on portfolio optimization model of Mean-Variance, where the average (mean) and volatility (variance) assumed the value is not constant, which is analyzed using time series model approach (time series). Non constant mean analyzed using models Autoregressive Moving Average (ARMA), whereas non constant volatility analyzed using models of the Generalized Autoregressive Conditional Hetroscedasticity (GARCH) [12]. Methods such analysis is then used to analyze a Islamic stock in Indonesia. for a further study, we analysis of portfolio is followe by performing the Genetic Algorithm. The Genetic Algorithm (GA) has been widely known as the robust method in solving many scientifical problem which has a non-linierity issue and complex solution [10]. The GA is one of a the purpose of this analysis is to obtain the proportion of investment capital allocation in some Islamic stocks are analyzed, which can provide a maximum return with a certain level of risk. heuristic method that is a branch of the evolutionary algorithm, which is a technique to solve complex optimization problems by mimicking the process of evolution of living things [9].

\section{Mathematical Model}

In this section will discuss the stages of analysis includes the calculation of stock returns, mean modeling, volatility modeling and portfolio optimization. 


\subsection{Stocks Return}

Suppose $P_{i t}$ Islamic stock price $i$ at time t, and $r_{i t}$ Islamic stock return $i$ at time t. The value of $r_{i t}$ can be calculated using the following equation.

$r_{i t}=\ln \left(\frac{P_{i t}}{P_{i t-1}}\right)$,

where $i=1, \ldots, N$ with $N$ number of stocks that were analyzed, and $t=1, \ldots, T$ with $T$ the number of stock price data observed ([14]; [13]).

\subsection{Mean Models}

Suppose $\left\{r_{i t}\right\}$ is Islamic stock return $i$ at time $t$ are stationary, will follow the model of $\operatorname{ARMA}(p, q)$ if for every $t$ have the following equation:

$r_{i t}-\phi_{1} r_{i t-1}-\ldots-\phi_{p} r_{i t-p}=a_{i t}+\theta_{1} a_{i t-1}+\ldots+\theta_{q} a_{i t-q}$

or can be written as

$r_{i t}=\phi_{1} r_{i t-1}+\ldots+\phi_{p} r_{i t-p}+a_{i t}+\theta_{1} a_{i t-1}+\ldots+\theta_{q} a_{i t-q},(2)$

where $\left\{a_{i t}\right\} \sim \mathrm{WN}\left(0, \sigma_{i}^{2}\right)$, which means sequence of residual

$\left\{a_{i t}\right\}$ normally distributed white noise with mean 0 and variance

$\sigma_{i}^{2}$. Sequence $\left\{r_{i t}\right\}$ is a model $\operatorname{ARMA}(p, q)$ with mean $\mu_{i t}$,

if $\left\{r_{t i}-\mu_{i t}\right\}$ is a model $\operatorname{ARMA}(p, q)$ ([6]; [11]).

Stages of the process modeling the mean include: (i) identification of the model, (ii) parameter estimation, (iii) diagnostic test, and (iv) Prediction [12].

\subsection{Volatility Models}

Volatility models in time series data in general can be analyzed using GARCH models. Suppose $\left\{r_{i t}\right\}$ is Islamic stock returns $i$ at time $t$ is stationary, the residuals of the mean model for Islamic stock $i$ at time $t$ is $a_{i t}=r_{t t}-\mu_{i t}$. Residual sequence $\left\{a_{i t}\right\}$ follow the model GARCH( $g, s)$ when for each has the following equation:

$$
\begin{aligned}
& a_{i t}=\sigma_{i t} \varepsilon_{i t}, \\
& \sigma_{i t}^{2}=\alpha_{i 0}+\sum_{k=1}^{g} \alpha_{i k} a_{i t-k}^{2}+\sum_{j=1}^{s} \beta_{i j} \sigma_{i t-j}^{2}+\varepsilon_{i t},
\end{aligned}
$$

with $\left\{\varepsilon_{i t}\right\}$ is a sequence of residual volatility models, namely the sequence of random variables are independent and identically distributed (IID) with mean 0 and variance 1 . Parameter coefficients satisfy the property that $\alpha_{i 0}>0, \alpha_{i k} \geq 0$,

$$
\beta_{i j} \geq 0 \text {, and } \sum_{k=1}^{\max (g, s)} \alpha_{i k}+\beta_{i j}<1 \text { ([12]; [14]). }
$$

Volatility modeling process steps include: (i) The estimated mean model, (ii) Test of ARCH effects, (iii) Identification of the model, (iv) The estimated volatility models, (v) Test of diagnosis, and (vi) Prediction [14].

\subsection{Prediction of 1 -Step Ahead}

Using the mean and volatility models, aiming to calculate the prediction of mean $\hat{\mu}_{i t}=\hat{r}_{i h}(l)$ and volatility $\hat{\sigma}_{i t}^{2}=\hat{\sigma}_{i h}^{2}(l)$, for $l$-period ahead of the starting point prediction $h$ ([14]; [2]). The prediction results of mean $\hat{\mu}_{t}=\hat{r}_{i h}(l)$ dan volatility $\hat{\sigma}_{i t}^{2}=\hat{\sigma}_{i h}^{2}(l)$, will then be used for portfolio optimization calculations below.

\subsection{Portfolio Optimization Model}

Suppose $r_{i t}$ Islamic stock return $i$ at time $t$, where $i=1, \ldots, N$ with $N$ the number of stocks that were analyzed, and $t=1, \ldots, T$ with $T$ the number of Islamic stock price data observed. Suppose also $\mathbf{w}^{\prime}=\left(w_{1}, \ldots, w_{N}\right)$ weight vector, $\mathbf{r}^{\prime}=\left(r_{1 t}, \ldots, r_{N t}\right)$ vector stock returns, and $\mathbf{e}^{\prime}=(1, \ldots, 1)$ unit vector. Portfolio return can be expressed as $r_{p}=\mathbf{W}^{\prime} \mathbf{r}$ with $\mathbf{w}^{\prime} \mathbf{e}=1$ ( [16]; [9]). Suppose $\boldsymbol{\mu}^{\prime}=\left(\mu_{1 t}, \ldots, \mu_{N t}\right)$, expectations of portfolio $\mu_{p}$ can be expressed as:

$\mu_{p}=E\left[r_{p}\right]=\mathbf{w}^{\prime} \boldsymbol{\mu}$.

Suppose given covariance matrix $\boldsymbol{\Sigma}=\left(\sigma_{i j}\right)_{i, j=1, \ldots, N}$, where $\sigma_{i j}=\operatorname{Cov}\left(r_{i t}, r_{j t}\right)$. Variance of the portfolio return can be expressed as follows:

$\sigma_{p}^{2}=\mathbf{w}^{\prime} \mathbf{\Sigma} \mathbf{w}$

Definition 1. [9]. A portfolio $p^{*}$ called (Mean-variance) efficient if there is no portfolio $p$ with $\mu_{p} \geq \mu_{p^{*}}$ and $\sigma_{p}^{2}<\sigma_{p^{*}}^{2}$ [9].

To get efficient portfolio, typically using an objective function to maximize

$2 \tau \mu_{p}-\sigma_{p}^{2}, \tau \geq 0$

where the parameters of the investor's risk tolerance. Means, for investors with risk tolerance $\tau(\tau \geq 0)$ need to resolve the problem of portfolio

Maximize $\left\{2 \tau \mathbf{w}^{\prime} \boldsymbol{\mu}-\mathbf{w}^{\prime} \mathbf{\Sigma} \mathbf{w}\right\}$

the condition $\mathbf{w}^{\prime} \mathbf{e}=1$

Please note that the completion of (6), for all $\tau \in[0, \infty)$ form a complete set of efficient portfolios. Set of all points in the diagram$\left(\mu_{p}, \sigma_{p}^{2}\right)$ related to efficient portfolio so-called surface efficient (efficient prontier) ([5]: [15]).

Equation (6) is the optimization problem of quadratic convex [9]. Lagrangian multiplier function of the portfolio optimization problem is given by

$L(\mathbf{w}, \lambda)=2 \tau \mathbf{w}^{\prime} \boldsymbol{\mu}-\mathbf{w}^{\prime} \boldsymbol{\Sigma} \mathbf{w}+\lambda\left(\mathbf{w}^{\prime} \mathbf{e}-1\right)$ 
Based on the Kuhn-Tucker theorem, the optimality condition of equation (7) is $\frac{\partial L}{\partial \mathbf{w}}=0$ and $\frac{\partial L}{\partial \lambda}=0$. Completed two conditions of optimality mentioned equation, the equation would be the optimal portfolio weights as follows:

$$
\mathbf{W}^{*}=\frac{1}{\mathbf{e}^{\prime} \boldsymbol{\Sigma}^{-1} \mathbf{e}} \boldsymbol{\Sigma}^{-1} \mathbf{e}+\tau\left\{\boldsymbol{\Sigma}^{-1} \boldsymbol{\mu}-\frac{\mathbf{e}^{\prime} \boldsymbol{\Sigma}^{-1} \boldsymbol{\mu}}{\mathbf{e}^{\prime} \boldsymbol{\Sigma}^{-1} \mathbf{e}} \boldsymbol{\Sigma}^{-1} \mathbf{e}\right\} .
$$

Furthermore, with substituting $\mathbf{W} *$ into equation (4) and (5), respectively obtained the values of the expectation and variance of the portfolio [13]. As a numerical illustration, will be analyzed some Islamic stocks as the following.

\subsection{Genetic Algorithm Optimization Model}

Genetic algorithms can be understood as a search method based on the mechanisms of scientific genetics and natural selection [5]. The mechanisms of scientific genetics reflect the ability of individuals to marry, and produce offspring that have characteristics similar to their parents. While the mechanism of natural selection states that living things can survive, if able to adapt to the environment [8]. Therefore, it is expected that the resulting offspring have the best combination of characteristics from their parents, and can sustain future generations.

The general structure of a genetic algorithm can be expressed as the following steps [12]:

a) Generating the initial population, this initial population is generated randomly so as to obtain an initial solution;

b) The population itself consists of a number of chromosomes that present the desired solution; c) Forming a new generation, in forming a new generation used three operators, namely reproduction / selection, cross over and mutation; Evaluation of the solution, this process will evaluate each population by calculating the fitness value of each chromosome, and evaluating it until the stop criteria are met. If the stopping criteria have not been met, it will be formed again new generation by repeating steps $b$ ).

\section{Methodology}

In this section will discuss the application of the method and the results of the analysis stage of the observation that includes Islamic stocks data, the calculation of Islamic stock returns, modeling the mean of Islamic stocks, volatility modeling, prediction of the mean and variance values, the process of optimization.

\subsection{I. slamic Stocks Data}

The data used in this study is secondary data, in the form of time series data (time series) of some of the daily stock price Islamic, which includes the names of Islamic stocks: AKRA, CPIN, ITMG, MYOR, and TLKM. Islamic stock price data, the data used is the closing Islamic stock price, for over 1360 days starting from January 1, 2008 till June 30, 2013 were downloaded from www.finance.yahoo.com [10]. Stock prices data will then be processed by using statistical software of Eviews-6 and Matlab.

\section{2 .Islamic Stocks Return and Stationarity}

Islamic stock returns of five firms in this study was calculated using equation (1). In Figure-1 below indicates the five Islamic stock chart returns are analyzed.

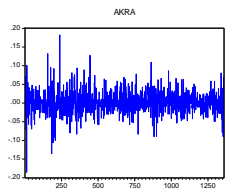

AKRA

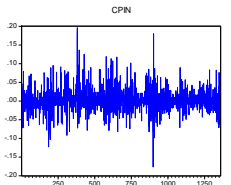

CPIN

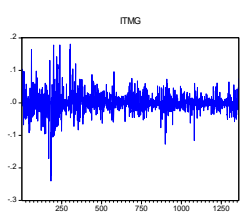

ITMG

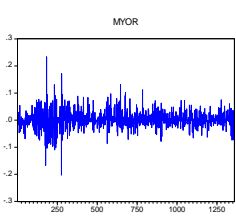

MYOR

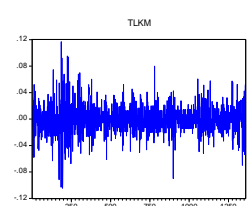

TLKM

Figure-1 Five Islamic Stock Charts

Can be seen by naked eye chart in Figure-1 shows that the five Islamic stock return data were analyzed (have stationary). For stationary testing is done using the $\mathrm{ADF}$ test statistic results respectively values are: -34.24848 ; $-33.79008 ;-30.20451$; -40.04979 ; and-28.36974. Further, if the specified level of significance $\quad \alpha=5 \%$, can be obtained by a standard normal distribution critical value is -2.863461 . It is clear that the value of the test statistic for all ADF of Islamic stocks are analyzed located in the rejection region, so that everything is stationary.

\section{3 .Mean Modeling of Islamic Stocks Return}

Islamic stock return data will be used to estimate mean model using the software of Eviews-6. First, the identification and estimation of mean model, carried out through the sample autocorrelation function (ACF) and partial autocorrelation function (PACF). Based on the pattern of ACF and PACF, tentative models can be specified from each Islamic stock returns. The estimation results indicated that the best models are respectively ARMA $(1,0)$, ARMA $(1,0)$, ARMA (1,0), ARMA $(7,0)$, and ARMA $(2,0)$. Second, the significance test for parameters and significance tests for models indicate that the mean model for all Islamic stocks analyzed have significance. Third, diagnostic tests for these models is done by using the data residual correlogram and Ljung-Box test hypotheses.
The test results show the residuals of the models are white noise. Results residual normality test showed normal distribution. Therefore residuals for all Islamic stock has been analyzed is white noise.

Equations of the results mean modeling for the five Islamic stock will be written simultaneously with the volatility models each of Islamic stocks, which will be estimated following.

\section{4 .Volatility Modeling of Islamic Stocks Return}

Modeling of volatility in this section is done by using statistical software of Eviews-6. First, carried out the detection elements of autoregressive conditional heteroscedasticity $(\mathrm{ARCH})$ to the residual $a_{t}$, using the ARCH-LM test statistic. Statistical value of the results obtained $\chi^{2}$ (obs*R-Square) each of Islamic stock returns AKRA, CPIN, ITMG, MYOR, and TLKM respectively are: $31.76757 ; 76.75431 ; 40.55526 ; 48.58576 ; 9.270781$, and 125.2410 by probability each of 12:05 0.0000 or smaller, which means that there are elements of ARCH.

Second, the identification and estimation of volatility models. This study used models of generalized autoregressive conditional heterscedasticity $(\mathrm{GARCH})$ which refers to equation (3). Based on 
squared residuals correlogram $a_{t}^{2}$, the ACF and PACF graphs of each, selected models of volatility that might be tentative. Volatility model estimation each of Islamic stock return performed simultaneously (synchronously) with mean models. After going through tests of significance for parameters and significance tests for models, all equations are written below have been significant. The result, obtained the best model are respectively:

$>$ Islamic stock AKRA follow the model ARMA(1,0)-GARCH(1,1) with equation:

$r_{t}=0.073891 r_{t-1}+a_{t} \quad$ and $\sigma_{t}^{2}=0.000014+0.040015 \alpha_{t-1}^{2}+0.9404318 \sigma_{t-1}^{2}+\varepsilon_{t}$

Islamic stock MYOR follow the model $\operatorname{ARMA}(7,0)-\mathrm{GARCH}(1,1)$ with equation:

$$
\begin{aligned}
& r_{t}=0.102007 r_{t-7}+a_{t} \quad \text { and } \\
& \sigma_{t}^{2}=0.000009+0.044332 \alpha_{t-1}^{2}+0.945801 \sigma_{t-1}^{2}+\varepsilon_{t}
\end{aligned}
$$

$>$ Islamic stock TLKM follow the model $\operatorname{ARMA}(2,0)-\operatorname{GARCH}(1,1)$ with equation:

$$
r_{t}=-0.084289 r_{t-2}+a_{t}
$$

and

$$
\sigma_{t}^{2}=0.000019+0.139166 \alpha_{t-1}^{2}+0.824540 \sigma_{t-1}^{2}+\varepsilon_{t}
$$

Based on the ARCH-LM test statistics, the residuals of the models for Islamic stock AKRA, CPIN, IMTG, MYOR, and TLKM there is no element of ARCH, and also has white noise. Mean and volatility models are then used to calculate the values

$>$ Islamic stock CPIN follow the model $\hat{\mu}_{t}=\hat{r}_{t}(l)$ and $\hat{\sigma}_{t}^{2}=\sigma_{t}^{2}(l)$ recursively.

ARMA(1,0)-GARCH(1,1) with equation:

$r_{t}=0.089639 r_{t-1}+a_{t}$

and $\quad 3.5$ Prediction of Mean and Variance Values

$\sigma_{t}^{2}=0.000052+0.134049 \alpha_{t-1}^{2}+0.820716 \sigma_{t-1}^{2}+\varepsilon_{t}$

$>$ Islamic stock ITMG follow the model

$\operatorname{ARMA}(1,0)-G A R C H(1,1)$ with equation:

$r_{t}=0.193825 r_{t-1}+a_{t}$

$\sigma_{t}^{2}=0.000012+0.066024 \alpha_{t-1}^{2}+0.923108 \sigma_{t-1}^{2}+\varepsilon_{t}$

Table-1: Predictive Values of Mean and Variance One Period AheadFor Each Islamic Stocks

\begin{tabular}{|l|l|l|l|}
\hline $\begin{array}{l}\text { Islamic } \\
\text { Stocks }\end{array}$ & $\begin{array}{l}\text { Model of } \\
\text { Mean-Volatility }\end{array}$ & $\begin{array}{l}\text { Mean } \\
\left(\hat{\mu}_{t}\right)\end{array}$ \\
\hline AKRA & ARMA(1,0)-GARCH(1,1) & $\begin{array}{l}\text { Variance } \\
\left(\hat{\sigma}_{t}^{2}\right)\end{array}$ & 0.001200 \\
\hline CPIN & ARMA(1,0)-GARCH(1,1) & 0.001407 & 0.001840 \\
\hline IMTG & ARMA(1,0)-GARCH(1,1) & 0.014619 & 0.001078 \\
\hline MYOR & ARMA(7,0)-GARCH(1,1) & 0.004940 & 0.000956 \\
\hline & ARMA(2,0)-GARCH(1,1) & 0.004406 & 0.001399 \\
\hline
\end{tabular}

\subsection{Mean-Variance Portfolio Optimization}

In this part done the process of portfolio optimization calculations. Portfolio optimization done with referring to the equation (6) using genetic algorithm optimization.

In order to solve the equation (6), we applied the GA proposed by Holland in 1975 [14]. The GA initially generates a random value of 'gen' $\mathbf{w}^{T}$ within a certain interval, which is associated in a 'chromosome'. This algorithm allows the competition between each chromosome [15], which brings each potential solution to the optimization problem. A set of chromosome called 'population' hence performed an iteration (generation) to determine the fittest parameters of the 'objective function'. In this case, the equation (6) is the objective function. The generation process consist of evaluating the 'fitness function' adapted to create a new population until the optimum chromosomes has been addressed. This operation is made by setting the genetic operator: number of population and Chromosome are 100 and 5, number of generation is 1000, the cross over and mutation rate are set to be 0.25 .

For an ideal state, we assume that $\mathbf{w}^{T} \mathbf{I}$ is equal to 1 hence 'controlled' fitness function is

$$
\begin{aligned}
& \mathbf{w}^{T} \mathbf{I}=V_{0} \\
& \mathbf{w}^{T} \mathbf{I}-V_{0}=0
\end{aligned}
$$

where $\mathbf{I}^{T}=(1,1,1,1)$. Which refer to the equation (5) as the objective functions.

Since we wanted to maximize the objective function, we adopted the 'Roulette-Wheel' selection, so that the value of $e^{U}$ are greater than 0 . Where $U$ is the objective functions. The selection of the new individual follows this formula [15]

$$
w_{i}=\frac{f_{i}}{\sum_{i=1}^{n} f_{i}}
$$

where $w_{i}$ is the new individual of each $\mathbf{w}$ and $f$ is the fitness value for each individual. $n$ is the size of population. In this case, we applied a random cross over and mutation algorithm which has a probability of 0.25 for each gen in the chromosomes to be crossed over or mutated [15].

The data used for process optimization are the values of the mean and variance are given in Table 2 . Using the values of mean in Table 2, column $\hat{\mu}_{t}$, used to form the mean vector as:

$\boldsymbol{\mu}^{T}=\left(\begin{array}{llll}0.001407 & 0.004919 & 0.014656 & 0.004940\end{array}\right.$

$0.004406)$

, amount of the Islamic stock that were analyzed were $=\mathbf{e}^{T}=\left(\begin{array}{lllll}1 & 1 & 1 & 1 & 1\end{array}\right)$. 
Furthermore, by using the values of variance in Table-2, column $\hat{\sigma}_{t}^{2}$, and together with the values of the covariance between

\footnotetext{
$\left(\begin{array}{llllll}0.001200 & 0.000136 & 0.000251 & 0.000113 & 0.000401\end{array}\right)$ $\begin{array}{llllll}0.000136 & 0.001840 & 0.000092 & 0.000315 & 0.000225\end{array}$ $\boldsymbol{\Sigma}=\mid \begin{array}{llllll}0.000251 & 0.000092 & 0.001078 & 0.000512 & 0.000133\end{array}$ $\begin{array}{llllll}0.000113 & 0.000315 & 0.000512 & 0.000956 & 0.000075\end{array}$ $\left.\begin{array}{llllll}0.000401 & 0.000225 & 0.000133 & 0.000075 & 0.001399\end{array}\right)$
} and

Optimization done in order to determine the composition of the portfolio weights, and thus the portfolio weight vector is determined by using equation (8). The weight vector calculation process, the values of risk tolerance $\tau$ determined by the simulation begins value $\tau=0.000$ with an increase of 0.001 . If it is
Islamic stocks, used to form the covariance matrix $\Sigma$ and the inverse matrix $\boldsymbol{\Sigma}^{-1}$ as follows:

Table-2. Process of Mean-Variance Portfolio Optimization using Genetic Algorithm

\begin{tabular}{|c|c|c|c|c|c|c|c|c|c|c|}
\hline$\tau$ & $w_{1}$ & $w_{2}$ & w3 & $w_{4}$ & $w_{5}$ & $\mathbf{w}^{T} \mathbf{e}$ & $\hat{\mu}_{p}$ & $\hat{\sigma}_{p}^{2}$ & $\hat{\mu}_{p}-\hat{\sigma}_{p}^{2}$ & $\hat{\mu}_{p} / \hat{\sigma}_{p}^{2}$ \\
\hline & AKRA & CPIN & IMTG & MYOR & TLKM & Sum & Mean & Variance & Maximum & Ratio \\
\hline 0.000 & 0.2150 & 0.1406 & 0.1895 & 0.2629 & 0.1920 & 1 & 0.0059 & 0.00043136 & 0.00546864 & 13.7161 \\
\hline 0.001 & 0.2093 & 0.1411 & 0.2025 & 0.2555 & 0.1916 & 1 & 0.0061 & 0.00043151 & 0.00566849 & 14.0507 \\
\hline 0.002 & 0.2036 & 0.1417 & 0.2155 & 0.2480 & 0.1913 & 1 & 0.0062 & 0.00043195 & 0.00576805 & 14.6893 \\
\hline 0.003 & 0.1978 & 0.1422 & 0.2285 & 0.2406 & 0.1909 & 1 & 0.0064 & 0.00043268 & 0.00596732 & 14.6893 \\
\hline 0.004 & 0.1921 & 0.1428 & 0.2414 & 0.2331 & 0.1905 & 1 & 0.0065 & 0.00043370 & 0.00606630 & 14.9921 \\
\hline 0.005 & 0.1864 & 0.1433 & 0.2544 & 0.2257 & 0.1902 & 1 & 0.0066 & 0.00043502 & 0.00616498 & 15.2832 \\
\hline 0.006 & 0.1807 & 0.1439 & 0.2674 & 0.2182 & 0.1898 & 1 & 0.0068 & 0.00043663 & 0.00636337 & 15.5621 \\
\hline 0.007 & 0.1750 & 0.1444 & 0.2803 & 0.2108 & 0.1894 & 1 & 0.0069 & 0.00043853 & 0.00646147 & 15.8284 \\
\hline 0.008 & 0.1693 & 0.1450 & 0.2933 & 0.2033 & 0.1891 & 1 & 0.0071 & 0.00044073 & 0.00665927 & 16.0817 \\
\hline 0.009 & 0.1636 & 0.1455 & 0.3063 & 0.1959 & 0.1887 & 1 & 0.0072 & 0.00044322 & 0.00675678 & 16.3217 \\
\hline 0.010 & 0.1579 & 0.1461 & 0.3193 & 0.1884 & 0.1883 & 1 & 0.0074 & 0.00044600 & 0.00695400 & 16.5481 \\
\hline 0.011 & 0.1522 & 0.1466 & 0.3322 & 0.1810 & 0.1880 & 1 & 0.0075 & 0.00044907 & 0.00705093 & 16.7608 \\
\hline 0.012 & 0.1465 & 0.1472 & 0.3452 & 0.1736 & 0.1876 & 1 & 0.0077 & 0.00045344 & 0.00724656 & 16.9597 \\
\hline 0.013 & 0.1407 & 0.1477 & 0.3582 & 0.1661 & 0.1872 & 1 & 0.0078 & 0.00045610 & 0.00734390 & 17.1445 \\
\hline 0.014 & 0.1350 & 0.1483 & 0.3711 & 0.1587 & 0.1587 & 1 & 0.0080 & 0.00046005 & 0.00753995 & 17.3154 \\
\hline 0.015 & 0.1293 & 0.1488 & 0.3841 & 0.1512 & 0.1865 & 1 & 0.0081 & 0.00046430 & 0.00763570 & 17.4724 \\
\hline 0.016 & 0.1236 & 0.1494 & 0.3971 & 0.1438 & 0.1461 & 1 & 0.0083 & 0.00046884 & 0.00783116 & 17.6155 \\
\hline 0.017 & 0.1179 & 0.1499 & 0.4101 & 0.1363 & 0.1858 & 1 & 0.0084 & 0.00047367 & 0.00792633 & 17.7449 \\
\hline 0.018 & 0.1122 & 0.1505 & 0.4230 & 0.1289 & 0.1854 & 1 & 0.0086 & 0.00047879 & 0.00812121 & 17.8608 \\
\hline 0.019 & 0.1065 & 0.1510 & 0.4360 & 0.1214 & 0.1850 & 1 & 0.0087 & 0.00048421 & 0.00821579 & 17.9633 \\
\hline 0.020 & 0.1008 & 0.1516 & 0.4490 & 0.1140 & 0.1847 & 1 & 0.0088 & 0.00048992 & 0.00831008 & 18.0528 \\
\hline 0.021 & 0.0951 & 0.1521 & 0.4619 & 0.1065 & 0.1843 & 1 & 0.0090 & 0.00049592 & 0.00850408 & 18.1295 \\
\hline 0.022 & 0.0893 & 0.1527 & 0.4749 & 0.0991 & 0.1840 & 1 & 0.0091 & 0.00050221 & 0.00859779 & 18.1937 \\
\hline 0.023 & 0.0836 & 0.1533 & 0.4879 & 0.0916 & 0.1836 & 1 & 0.0093 & 0.00050880 & 0.00879120 & 18.2459 \\
\hline 0.024 & 0.0779 & 0.1538 & 0.5009 & 0.0842 & 0.1832 & 1 & 0.0094 & 0.00051568 & 0.00888432 & 18.2863 \\
\hline 0.025 & 0.0722 & 0.1544 & 0.5138 & 0.0767 & 0.1829 & 1 & 0.0096 & 0.00052285 & 0.00907715 & 18.3154 \\
\hline 0.026 & 0.0665 & 0.1549 & 0.5268 & 0.0693 & 0.1825 & 1 & 0.0097 & 0.00053032 & 0.00916968 & 18.3336 \\
\hline 0.027 & 0.0608 & 0.1555 & 0.5398 & 0.0619 & 0.1821 & 1 & 0.0099 & 0.00053808 & 0.00936192 & 18.3413 \\
\hline 0.028 & 0.0551 & 0.1560 & 0.5527 & 0.0544 & 0.1818 & 1 & 0.0100 & 0.00054613 & 0.00945387 & 18.3390 \\
\hline 0.029 & 0.0494 & 0.1566 & 0.5657 & 0.0470 & 0.1814 & 1 & 0.0102 & 0.00055447 & 0.00964553 & 18.3270 \\
\hline 0.030 & 0.0437 & 0.1571 & 0.5787 & 0.0395 & 0.1810 & 1 & 0.0103 & 0.00056311 & 0.00973689 & 18.3059 \\
\hline 0.031 & 0.0380 & 0.1577 & 0.5917 & 0.0321 & 0.1807 & 1 & 0.0105 & 0.00057204 & 0.00992796 & 18.2760 \\
\hline 0.032 & 0.0322 & 0.1582 & 0.6046 & 0.0246 & 0.1803 & 1 & 0.0106 & 0.00058126 & 0.01001874 & 18.2379 \\
\hline 0.033 & 0.0265 & 0.1588 & 0.6176 & 0.0172 & 0.1799 & 1 & 0.0107 & 0.00059078 & 0.01010922 & 18.1919 \\
\hline 0.034 & 0.0208 & 0.1593 & 0.6306 & 0.0097 & 0.1796 & 1 & 0.0109 & 0.00060059 & 0.01029941 & 18.1386 \\
\hline 0.035 & 0.0151 & 0.1599 & 0.6435 & 0.0023 & 0.1792 & 1 & 0.0110 & 0.00061069 & 0.01038931 & 18.0783 \\
\hline 0.036 & 0.0094 & 0.1604 & 0.6565 & -0.0052 & 0.1788 & 1 & 0.0112 & 0.00062108 & 0.01057892 & 18.0115 \\
\hline
\end{tabular}

\section{Result and Discussion}

Based on the results of the optimization process are given in Table-2, the pair of points $\quad\left(\hat{\mu}_{p}, \hat{\sigma}_{p}^{2}\right)$ efficient portfolio can be formed or the so-called efficient frontier as given in Figure-2.a. This graph shows the efficient frontier decent area for investors with different levels of risk tolerance, to make an investment. Also by using the optimization process results in

$$
\Sigma^{-1}=10^{3} \times\left(\begin{array}{rrrrr}
0.9613 & -0.0345 & -0.2020 & 0.0257 & -0.2522 \\
-0.0345 & 0.5904 & 0.0738 & -0.2237 & -0.0801 \\
-0.2020 & 0.0738 & 1.3037 & -0.6955 & -0.0406 \\
0.0257 & -0.2237 & -0.6955 & 1.4880 & 0.0150 \\
-0.2522 & -0.0801 & -0.0406 & 0.0150 & 0.8030
\end{array}\right)
$$

assumed that short sales are not allowed, then the simulation is stopped when the value of $\tau=0.036$, because it has resulted in a portfolio weight at least there is a negative value. The portfolio weights calculation results are given in Table- 2 . 


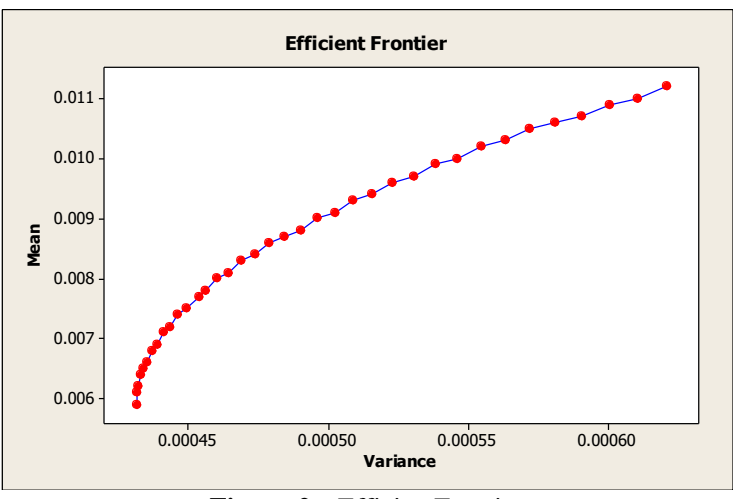

Figure-2.a Efficien Frontier

Based on the results of the calculation of portfolio optimization, the optimum value is achieved when the value of the portfolio's risk tolerance $\tau=0.027$. The portfolio produces mean value of $\hat{\mu}_{p}=0.0099 \quad$ with the value of risk as the variance $\hat{\sigma}_{p}^{2}=$ 0.00053808 .

Composition weight of the maximum portfolio respectively are: $0.0608,0.1555,0.5398,0.0619$, and 0.1821 . This provides reference to investors that invest in Islamic stocks of AKRA, CPIN, ITMG, MYOR, and TLKM, in order to achieve the maximum value of the portfolio, the composition of the portfolio weights are as mentioned above.

\section{Conclusions}

In this paper we analyzed the Mean-Variance portfolio optimization on some Islamic stocks by using Genetic Algorithm approaches, in some Islamic stocks are traded in the Islamic capital market in Indonesia. The analysis showed that some of Islamic stocks which analyzed all follow the ARMA( $p, q)$-GARCH$(g, s)$ models. Whereas, Based on the results of the calculation of portfolio optimization, produced that the optimum is achieved when the composition of the portfolio investment weights in Islamic stocks of AKRA, CPIN, ITMG, MYOR, and TLKM, respectively are: $0.0608,0.1555,0.5398$, 0.0619 , and 0.1821 . The composition of the portfolio weights thereby will produces a portfolio with mean value of 0.0099 and the value of risk, measured as the variance of 0.00053808 .

\section{References}

[1] El hachlou, M., Guennoun, Z. and Hamza, F. 2012. Stocks Portfolio Optimization Using Classification and Genetic Algorithms. Applied Mathematical Sciences, Vol. 6, 2012, no. 94 , pp. $4673-4684$.

[2] Febrian, E. \& Herwany, A. (2009). Volatility Forecasting Models and Market Co-Integration: A Study on South-East Asian Markets. Working Paper in Economics and Development Studies. Department of Ekonomics, Padjadjaran University.

[3] Kapiamba, J.N., Ulungu, B.E.L., and Mubenga, P.K. 2015. Simulated Annealing vs Genetic Algorithm to Portfolio Selection. International Journal of Scientific and Innovative Mathematical Research (IJSIMR), Volume 3, Issue 5, May 2015, PP $18-30$.

[4] ISSN 2347-307X (Print) \& ISSN 2347-3142 (Online). http://www.arcjournals.org.

[5] Goto, S. \& Yan Xu. (2012). On Mean Variance Portfolio Optimization: Improving Performance Through Better Use of Hedging Relations. Working Paper. Moore School of Business, University of South Carolina. email: shingo.goto@moore.sc.edu.

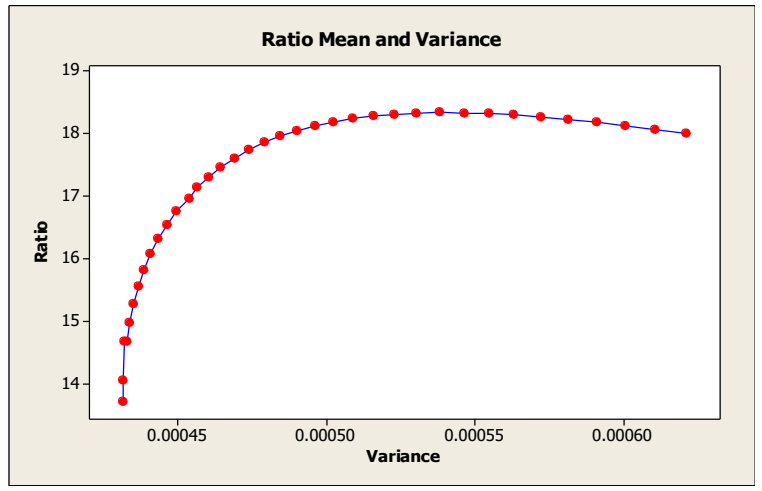

Figure-2.b. Ratio of Mean-Variance

[6] Gujarati, D.N. (2004). Basic Econometrics. Fourth Edition. The McGraw-Hill Companies, Arizona.

[7] Kheirollah, A. \& Bjarnbo, O., (2007). A Quantitative Risk Optimization of Markowitz Model: An Empirical Investigation on Swedish Large Cap List, Master Thesis, in Mathematics/Applied Mathematics, University Sweden, Department of Mathematics and Physics, www.mdh.se/polopoly_fs/ 1.16205!MasterTheses.pdf.

[8] Lin, C.C. and Liu, Y.T. 2008. Genetic Algorithms for Portfolio Selection Problems with Minimum Transaction Lots. European Journal of Operational Research 185 (2008), pp. 393-404.

[9] Panjer, H.H. Ed., et al. (1998). Financial Economics: With Applicationsto Investments, Insurance, and Pensions. Schaumburg, Ill.: The Actuarial Foundation.

[10] Rifqiawan, R.A. (2008). Analisis Perbedaan Volume Perdagangan Saham-Saham yang Optimal Pada Jakarta Islamic Index (JII) di Bursa Efek Indonesia (BEI). Tesis Program Magister. Program Stdi Magister Sains Akuntansi, Program Pascasarjana, Universitas Diponegoro, Semarang, 2008.

[11] Shewhart, Walter A and Samuel S. Wilks. (2004). Applied Econometric Time Series. John Wiley \&Sons, Inc. United States of America.

[12] Shi-Jie Deng. (2004). Heavy-Tailed GARCH models: Pricing and Risk Management Applications in Power Market, IMA Control \& Pricing in Communication \& Power Networks. 7-17 Mar http://www.ima.umn.edu/talks/.../deng/power_ workshop_ ima032004-deng.pdf.

[13] Sukono, Subanar \& Dedi Rosadi. (2011). Pengukuran VaR Dengan Volatilitas Tak Konstan dan Efek Long Memory. Disertasi. Prtogram Studi S3 Statistika, Jurusan Matematika, Fakultas Matematika dan Ilmu Pengetahuan Alam, Universitas Gajah Mada, Yogyakarta, 2011.

[14] Tsay, R.S. (2005). Analysis of Financial Time Serie, Second Edition, USA: John Wiley \& Sons, Inc.

[15] Yoshimoto, A. (1996). The Mean-Variance Approach To Portfolio Optimization Subject To Transaction Costs. Journal of the Operations Research Society of Japan, Vol. 39, No. 1, March 1996

[16] Zhang, D., (2006). Portfolio Optimization with Liquidity Impact, Working Paper, Center for Computational Finance and Economic Agents, University of Essex, www.orfe.princeton.edu/ oxfordprinceton5/slides/yu.pdf. 